\title{
Review
}

\section{Does Developmental Variability in the Number of Midbrain Dopamine Neurons Affect Individual Risk for Sporadic Parkinson's Disease?}

\author{
Christian U. von Linstow ${ }^{\mathrm{a}, *}$, Merritt DeLano-Taylor ${ }^{\mathrm{a}, \mathrm{b}}$, Jeffrey H. Kordower ${ }^{\mathrm{c}}$ and Patrik Brundin ${ }^{\mathrm{a}}$ \\ ${ }^{a}$ Center for Neurodegenerative Science, Van Andel Institute, Grand Rapids, MI, USA \\ ${ }^{\mathrm{b}}$ Department of Biomedical Sciences, Grand Valley State University, Allendale, MI, USA \\ ${ }^{\mathrm{c}}$ Department of Neurological Sciences, Rush University Medical Center, Chicago, IL, USA
}

Accepted 21 December 2019

\begin{abstract}
Parkinson's disease (PD) is a slowly progressing neurodegenerative disorder that is coupled to both widespread protein aggregation and to loss of substantia nigra dopamine (DA) neurons, resulting in a wide variety of motor and nonmotor signs and symptoms. Recent findings suggest that the PD process is triggered several years before there is sufficient degeneration of DA neurons to cause onset of overt motor symptoms. According to this concept, the number of DA neurons present in the substantia nigra at birth could influence the time from the molecular triggering event until the clinical diagnosis with lower number of neurons at birth increasing the risk to develop the disease. Conversely, the risk for diagnosis would be reduced if the number of DA neurons is high at birth. In this commentary, we discuss the genetic and epigenetic factors that might influence the number of nigral DA neurons that each individual is born with and how these may be linked to PD risk.
\end{abstract}

Keywords: Parkinson's disease risk, dopamine neuron number, substantia nigra, neural development, motor dysfunction, cis-regulation

\section{INTRODUCTION}

Parkinson's disease (PD) is a progressive neurodegenerative disease that is associated with a characteristic set of motor and non-motor disturbances. Most cardinal motor symptoms such as bradykinesia, rigidity, and postural instability, and to a lesser extent tremor, are considered largely a consequence of loss of striatal dopamine (DA), secondary to the degeneration of DA neurons in the substantia

\footnotetext{
${ }^{*}$ Correspondence to: Christian U. von Linstow, Center for Neurodegenerative Science, Van Andel Institute, 333 Bostwick Avenue, NE, Grand Rapids, MI 49503, USA. Tel.: +1 616234 5853; E-mail: Christian.linstow@vai.org.
}

nigra [1]. Another major neuropathological finding is widespread accumulation of alpha-synuclein $(\alpha-$ syn) in neuronal perikarya and neurites [2], which is believed to contribute to both motor and nonmotor deficits. These disease features are apparent in common idiopathic PD, as well as rare familial cases with single point mutations or gene duplications and triplications of $\alpha$-syn [3]. Several other autosomal dominant (with variable penetrance) and recessive familial $\mathrm{PD}$ genes have been identified, although a definitive disease mechanism has not yet been identified for these mutations [4]. In addition, a growing number of single nucleotide polymorphisms are known to influence PD risk [5]. These genetic 
loci clearly influence disease risk in the approximate $90 \%$ of PD patients that are classified as having idiopathic disease. Notably, while heritability has been estimated to underlie around $25 \%$ of PD risk [6], environmental factors and age are more impactful on disease risk in sporadic cases [7]. It is believed that the loss of striatal DA, with concomitant degeneration of nigral DA neurons, has to exceed a certain threshold before motor symptoms are evident, and the clinical diagnosis of PD can be made. Therefore, the number of nigral DA neurons that are present at birth might influence the lifetime risk of being diagnosed with PD. The purpose of this short review is threefold. First, to discuss the literature describing variability in numbers of nigral DA neurons between normal individuals. Second, to consider genetic as well as epigenetic/environmental factors that can influence this variability. Third, to propose a model for how the variability can impact lifetime PD risk.

\section{INTER-INDIVIDUAL DIFFERENCES IN DA CELL NUMBERS}

In this section, we first describe estimates of the proportion of nigral DA neurons reported to have died in PD patients coming to autopsy, and then we discuss the variation in number of nigral DA neurons found in brains of normal subjects.

The average reduction of nigral DA neurons determined by stereological estimates in 181 PD patients across 12 studies has been estimated to around $\sim 68 \%$ but reflected considerable inter-study and inter-individual variation [8]. The focus has not been on the absolute number of nigral DA neurons remaining in the PD patients' brains, but instead it has been on the number of remaining neurons expressed as a percentage of the numbers found in normal healthy subjects from the same study. Generally, it is believed that the absolute number of functional DA neurons remaining in the substantia nigra, not yet affected by the PD process, that decides when the "tipping point" is reached and significant clinical motor symptoms appear. The degeneration of nigral DA neurons considered to be progressive, in a linear or stepwise fashion, and starts many years before the first motor symptoms. Because there are no datasets of nigral DA neuron counts available from individuals who had recently exhibited onset of PD symptoms, it is not possible to state with confidence how many neurons must die before motor symptoms appear. These assumptions imply that the number of DA neurons that an individual is born with could influence the lifetime risk for PD.

Considering the potential importance of starting number of DA neurons for PD risk, it is pertinent to ask how many DA neurons are present in the normal human substantia nigra? Surprisingly, there is not a strong consensus on this in the literature. Early stereological studies of substantia nigra neurons in normal healthy humans have generally quantified neuromelanin-containing neurons (pigmented) on Nissl-stained tissue. This number generally correlates well with the number of tyrosine hydroxylase (TH) neurons [9], though age-related changes including the buildup of intracellular neuromelanin [10], and increases in monomeric $\alpha$-syn [11] may lead to phenotypic down-regulation in viable nigral neurons leading to discrepancies between the number of pigmented and TH-immunoreactive neurons in the same individual. The longstanding idea that the number of midbrain DA neurons present at birth might affect susceptibility to PD [12] was initially based on observations of mouse strain differences in the number of nigral TH-immunopositive neurons [12-14]. We assessed the literature to define a natural variation in the number of DA neurons in the substantia nigra of healthy humans. We focused on studies employing stereological approaches to quantify the numbers of pigmented neurons in the substantia nigra and observed a considerable variation in human subjects across four studies [9, 15-17] (Fig. 1A). To avoid confounding effects in the healthy human controls, the authors of the studies followed strict exclusion criteria such as history of neuropsychiatric diseases and/or presence of neuropathology with only minor differences. In the data presented by Pakkenberg et al. [15] the difference between the healthy human subjects with the lowest and highest number of pigmented neurons reached $152 \%\left(\sim 4.00-6.10 \times 10^{5}\right.$ neurons $)$, while the study by Ma et al. [16] revealed $433 \%$ in difference between the highest and lowest population size $\left(\sim 0.75-3.25 \times 10^{5}\right.$ neurons $)$. Cabello et al. [9] and Rudow et al. [17] presented ranges of $372 \%\left(\sim 1.74-6.49 \times 10^{5}\right.$ neurons $)$ and $220 \%$ $\left(\sim 2.32-5.13 \times 10^{5}\right.$ neurons $)$, respectively. We also specifically focused on data from individuals who died during the first five decades (18-50 years) to minimize the risk that any variance in cell number was due to aging or early stages of age-related, progressive disorders not yet discernable (Fig. 1B) [18]. In the 18-50 years dataset, the variation in the number of pigmented neurons in the nigra was still high. 


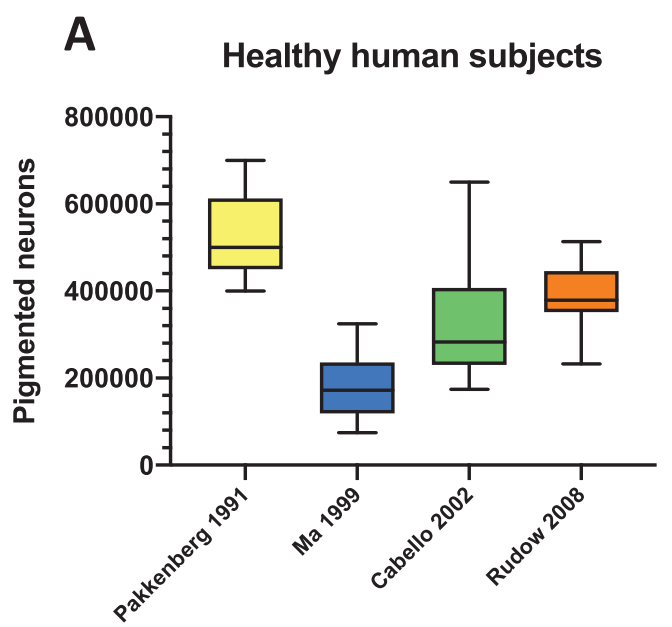

B

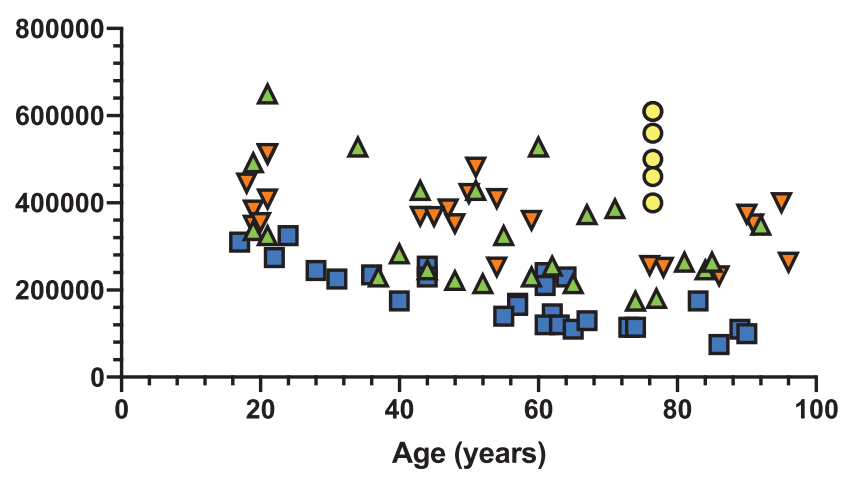

Fig. 1. Natural variation in the number of pigmented neurons in healthy human. Four studies employing stereological quantification of the number of nigral pigmented neurons [9, 15-17] were selected and (A) depicted in a box and whisker plot showing considerable variation in healthy human subjects. (B) The same data were also plotted against ageing where the first five decades where the brain should be relatively unaffected by various confounders (e.g., ageing) retains a high degree of variability in the number of pigmented neurons. Some aged individuals in the eighth and ninth decade show a very high number of pigmented neurons comparable to individuals in their twenties.

Across the studies listed in Fig. 1B, Ma et al. [16] reported a $185 \%$ difference in the subjects with lowest and highest number of pigmented neurons in the substantia nigra $\left(\sim 1.75-3.25 \times 10^{5}\right)$. Cabello et al. [9] reported a $293 \%$ difference $\left(\sim 2.21-6.49 \times 10^{5}\right)$ and Rudow et al. [17] reported a $147 \%$ difference $\left(\sim 3.48-5.13 \times 10^{5}\right)$ in the number of pigmented neurons (Fig. 1B). In short, all the available data sets we examined showed considerable natural variation in the numbers of nigral DA neurons.

\section{DOES THE INHERITED NUMBER OF NIGRAL DOPAMINE NEURONS AFFECT PD RISK?}

As mentioned above, the threshold for PD motor symptoms might be influenced by the starting number of nigral DA neurons at birth, or the number of cells that survive the immediate post-natal pruning of the nigrostriatal system (Fig. 2). In this section, we discuss this concept in more detail. The idea of high variability among DA neurons and its clinical implications was conceived more than five decades ago. It was based on observations showing considerable differences among inbred mouse strains relating to TH activity [19], DA neuron numbers and striatum size $[12,14,20]$. Recently, the genetic and epigenetic pathways that govern the development of nigral DA neurons have shed more light on this research area.

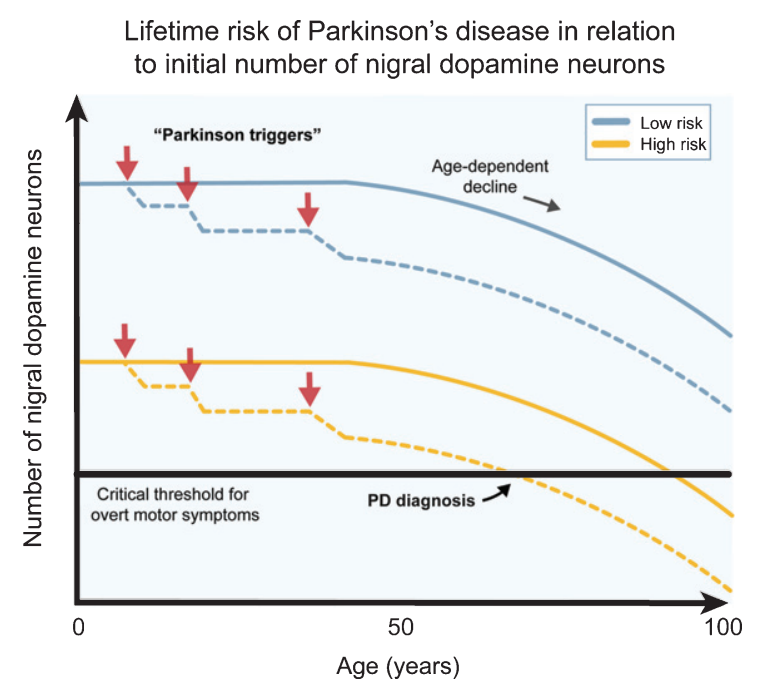

Fig. 2. The number of dopamine neurons and Parkinson's disease risk. Several genetic, epigenetic and non-genetic factors affect the generation of dopamine (DA) neurons and their survival during development and birth. This likely contributes to a natural high variation in healthy human subjects. Individuals born with higher number of DA neurons are more robust to Parkinson's disease (PD) triggers (red arrows) since they can afford a higher cell loss before onset of motor symptoms (blue lines), while individuals born with a smaller starting population of DA neurons can afford a much lower cell loss from the exposure to PD triggers before the onset of motor symptoms (yellow lines). The combination of PD triggers and the natural age-related decline of DA neurons may therefore put some individuals at a greater lifetime risk of acquiring PD motor symptom. The DA neuron pool from birth may therefore be an important parameter when considering PD risk. 
Formation of midbrain DA neurons is tightly orchestrated by the tempo-spatial expression of a group of highly conserved transcription factors (e.g., EN1/2, OTX2, GLI1/2, FOXA1/2, LMX1A/B, MSX1/2, NEUROG1, ASCL1 and NATO3) and morphogens (e.g., FGF8, WNT1 and SHH) that shape the rostro-caudal and dorso-ventral identities [21, 22]. Many of these genes are expressed in fully mature DA neurons, together with NURRI and PITX3, and are involved in adult neuron maintenance. Especially NURR1 is prerequisite for the expression of $T H$ and SLC6A3 that defines the midbrain DA phenotype [23]. Consequently, the substantia nigra DA population size is not only defined by a predetermined gene program, but also through how efficient cellular maintenance is for evading potential stress-related cell loss. This may further explain why polymorphisms in NURRI and PITX3 have been linked with PD risk [24, 25]. Insufficiency in transcription factor genes that govern nigral DA neuron development has been associated with rare developmental abnormalities in humans [26] and further detailed investigations in vivo specifically implicate these genes in determining the anatomical location, formation and size of the DA neuron population [22]. Ectopic or increased expression of genes such as FOXA2, LMX1A [27, 28], OTX2 [29] and CTNNBI [30] change the anatomical location or increase the size of the midbrain DA population in vivo. Mutations in the primary sequence of these genes are unlikely to be the source of the size variation in the midbrain DA population. Instead, fine-tuning of gene transcription via cis-regulating elements [31] is a possible central determinant of the inter-individual variation in the number of the substantia nigra neurons. Considering that the epigenetic landscape changes considerably from progenitor into post-mitotic neuron [32], it will be challenging to link the activation state, mutations or single nucleotide polymorphisms in these non-coding regions during embryogenesis with the number of DA neurons that are present at birth. Some tentative clues are appearing in the literature. In cells derived from human embryonic stem cells (hESC), a study recently tracked PD risk single nucleotide polymorphisms to the disruption of enhancers important for transcriptions factors involved in mesodermal differentiation [33]. One particular important mesodermal structure is the notochord that releases Shh, which is a secreted signaling molecule essential for the induction of the floor plate and hence the development of midbrain DA neurons. [33]. This suggests a potential link between a PD risk single nucleotide polymor- phism and epigenetic regulation of genes involved in the determination of the number of substantia nigra DA neurons. Studies characterizing induced pluripotent stem cells (iPSCs) have offered a potential link between a low number of nigral DA neurons and a PD mutation. Neural stem cells (NSCs) differentiated from iPSCs generated from an early onset PD patient with a PLAG26 mutation showed profound reduction in proliferation and differentiation of DA neurons in vitro [34]. Similar observations of reduced proliferation and differentiation capacity were observed in NSCs derived from LRRK2 mutant (G2019S) iPSCs after prolonged passaging [35]. Studies of DA neurons differentiated from iPSCs derived from sporadic and familial PD (LRRK2 G2019S, PINK Q456X and triSNCA) have demonstrated that the deficiencies observed in PD-derived NSCs seems to be passed on to the progeny $[34,36-39]$. These changes were only evident upon differentiation into DA neurons after prolonged culturing [40]. The methylation profiles of the cells derived from iPSCs from familial PD cases resembled cultures not enriched in DA neurons, suggesting an inherent inability to fully adapt the epigenetic identify of a healthy DA neurons [40]. These findings were integrated in a theoretical model where PD-related enhancer methylation was associated with the downregulation of a transcription factor network involved in neurogenesis and survival (HNF4A, FOXA1, NR3C1 and FOSL2) and upregulation of a transcription factor network $(O T X 2$, $P A X 6$ and ZIC1) and genes (SNCA, DCC and DCT) involved in proliferation, differentiation and survival (via $P A X 6$ ) [40]. Cell death is a naturally occurring event in the formation of the nigrostriatal circuitry at around post-natal day 2 and 14 in rodent nigral DA neurons [41]. Therefore, a reduced ability of PD iPSCs to tolerate stress in vitro might reflect how well the DA neurons are equipped to survive during early development in vivo, either during embryogenesis or shortly after birth.

A role of $\alpha$-syn in PD pathogenesis is well documented in the adult brain, but less so in early development. An in vivo study showed that the number of TH-immunoreactive neurons in the substantia nigra was affected by the expression of $\alpha$-syn in a gene dose dependent manner in mice [42]. High expression of $\alpha$-syn led to increased numbers of nigral TH-immunoreactive neurons in nigra and vice versa [42]. Interestingly, the effect of removing $\alpha$ syn expression specifically caused a reduction in the number of TH-immunoreactive neurons at embryonic day 13.5 (but not at day 10), approximately coincid- 
ing with the ontogenetic pruning of DA neurons that has been described to occur at embryonic day 14 [42]. This may be related to the reported ability of $\alpha$-syn to increase tolerance to oxidative stress [43, 44], and may consequently exert an important function during development and survival of DA neurons.

\section{THE ROLE OF NON-GENETIC FACTORS IN AFFECTING THE DA POPULATION BEFORE AND AT BIRTH}

Non-genetic factors in utero can also impact the critical periods of brain development when the DA neuron population is born and undergoes maturation, as well as the time window when a subset of the DA neurons is selected for developmental programmed cell death. Prenatal infections with influenza virus have been associated with increased risk of neuropsychological diseases and PD and is paralleled directly with apoptosis of DA neurons in the nigra [45]. Maternal inoculation with lipopolysaccharide is detrimental to TH neurons around E10.5 in the rat fetus [46] which is around the time that TH expression is turned on in the floor plate (E10.5-12.5) [22]. Exposure to environmental toxins during pregnancy or hypoxic conditions at birth may similarly affect DA neurons by disturbing mitochondrial function which is essential for proper neurogenesis and differentiation [47]. In addition to changing the number of DA neurons surviving at birth, or through the developmental period shortly thereafter, these factors might further impact sensitivity to additional insults that could occur in adulthood [48].

\section{CONCLUDING REMARKS}

The DA neuron is undoubtably in the front line when it comes to understanding PD risk genes, epigenetic changes and environmental factors (Fig. 2). In this commentary, we highlight that some of the genetic loci that now are known to influence PD risk might not impact death processes in dopamine neurons in the adult organism. Instead, we propose they influence lifetime risk of developing motor symptoms by affecting the number of nigral DA neurons that each individual is born with or that survives immediate postnatal development. The cell number that each individual has when leaving infanthood might further depend on non-genetic and non-epigenetic factors such as maternal infections and endogenous or environmental toxins that impact intrauterine health. Our most important take home message is that we need to explore changes that occur both during development and in during adulthood and aging when we seek to understand the full landscape of PD risk.

\section{ACKNOWLEDGMENTS}

P.B. is supported by grants from the National Institutes of Health (1R01DC016519-01, 5R21NS 093993-02, 1R21NS106078-01A1). P.B. reports additional awards from Office of the Assistant Secretary of Defense for Health Affairs (Parkinson's Research Program, Award No. W81XWH-17-10534), and the Peter C. and Emajean Cook Foundation, which are outside but relevant to the submitted work.

\section{CONFLICT OF INTEREST}

P.B. has received commercial support as a consultant from Axial Biotherapeutics, CuraSen, Fujifilm-Cellular Dynamics International, IOS Press Partners, LifeSci Capital LLC, Lundbeck A/S and Living Cell Technologies LTD. He has received commercial support for grants/research from Lundbeck $\mathrm{A} / \mathrm{S}$ and Roche. He has ownership interests in Acousort $\mathrm{AB}$ and Axial Biotherapeutics and is on the steering committee of the NILO-PD trial. J.H.K has received commercial support as a consultant from Cellular Dynamics International, Inc, Michael J. Fox Foundation, Abbvie, Exicure, NSGENE, Guidepoint, Inhibikhase, Axovant, and Seelos.

\section{REFERENCES}

[1] Cheng HC, Ulane CM, Burke RE (2010) Clinical progression in Parkinson disease and the neurobiology of axons. Ann Neurol 67, 715-725.

[2] Spillantini MG, Schmidt ML, Lee VM, Trojanowski JQ, Jakes R, Goedert M (1997) Alpha-synuclein in Lewy bodies. Nature 388, 839-840.

[3] Siddiqui IJ, Pervaiz N, Abbasi AA (2016) The Parkinson disease gene SNCA: Evolutionary and structural insights with pathological implication. Sci Rep 6, 24475.

[4] Klein C, Westenberger A (2012) Genetics of Parkinson's disease. Cold Spring Harb Perspect Med 2, a008888.

[5] Nalls MA, Blauwendraat C, Vallerga CL, Heilbron K, Bandres-Ciga S, Chang D, Tan M, Kia DA, Noyce AJ, Xue A, Bras J, Young E, von Coelln R, Simon-Sanchez J, Schulte C, Sharma M, Krohn L, Pihlstrom L, Siitonen A, Iwaki H, Leonard H, Faghri F, Gibbs JR, Hernandez DG, Scholz SW, Botia JA, Martinez M, Corvol JC, Lesage S, Jankovic J, Shulman LM, Sutherland M, Tienari P, Majamaa K, Toft M, Andreassen OA, Bangale T, Brice A, Yang J, Gan-Or Z, Gasser T, Heutink P, Shulman JM, Wood NW, Hinds DA, Hardy JA, Morris HR, Gratten J, Visscher PM, 
Graham RR, Singleton AB, 23 and Me Research Team; System Genomics of Parkinson's Disease Consortium; International Parkinson's Disease Genomics Consortium (2019) Identification of novel risk loci, causal insights, and heritable risk for Parkinson's disease: A meta-analysis of genome-wide association studies. Lancet Neurol 18, 1091-1102.

[6] Reynolds RH, Botia J, Nalls MA, International Parkinson's Disease Genomics C, System Genomics of Parkinson's D, Hardy J, Gagliano Taliun SA, Ryten M (2019) Moving beyond neurons: The role of cell type-specific gene regulation in Parkinson's disease heritability. NPJ Parkinsons Dis 5, 6.

[7] Vance JM, Ali S, Bradley WG, Singer C, Di Monte DA (2010) Gene-environment interactions in Parkinson's disease and other forms of parkinsonism. Neurotoxicology $\mathbf{3 1}$, 598-602.

[8] Giguere N, Burke Nanni S, Trudeau LE (2018) On cell loss and selective vulnerability of neuronal populations in Parkinson's disease. Front Neurol 9, 455.

[9] Cabello CR, Thune JJ, Pakkenberg H, Pakkenberg B (2002) Ageing of substantia nigra in humans: Cell loss may be compensated by hypertrophy. Neuropathol Appl Neurobiol 28, 283-291.

[10] Fedorow H, Halliday GM, Rickert CH, Gerlach M, Riederer P, Double KL (2006) Evidence for specific phases in the development of human neuromelanin. Neurobiol Aging 27, 506-512.

[11] Chu Y, Kordower JH (2007) Age-associated increases of alpha-synuclein in monkeys and humans are associated with nigrostriatal dopamine depletion: Is this the target for Parkinson's disease? Neurobiol Dis 25, 134-149.

[12] Ross RA, Judd AB, Pickel VM, Joh TH, Reis DJ (1976) Strain-dependent variations in number of midbrain dopaminergic neurones. Nature 264, 654-656.

[13] Baker H, Joh TH, Reis DJ (1980) Genetic control of number of midbrain dopaminergic neurons in inbred strains of mice: Relationship to size and neuronal density of the striatum. Proc Natl Acad Sci U S A 77, 4369-4373.

[14] Muthane U, Ramsay KA, Jiang H, Jackson-Lewis V, Donaldson D, Fernando S, Ferreira M, Przedborski S (1994) Differences in nigral neuron number and sensitivity to 1methyl-4-phenyl-1,2,3,6-tetrahydropyridine in C57/bl and CD-1 mice. Exp Neurol 126, 195-204.

[15] Pakkenberg B, Moller A, Gundersen HJ, Mouritzen Dam A, Pakkenberg H (1991) The absolute number of nerve cells in substantia nigra in normal subjects and in patients with Parkinson's disease estimated with an unbiased stereological method. J Neurol Neurosurg Psychiatry 54, 30-33.

[16] Ma SY, Roytt M, Collan Y, Rinne JO (1999) Unbiased morphometrical measurements show loss of pigmented nigral neurones with ageing. Neuropathol Appl Neurobiol 25, 394399.

[17] Rudow G, O’Brien R, Savonenko AV, Resnick SM, Zonderman AB, Pletnikova O, Marsh L, Dawson TM, Crain BJ, West MJ, Troncoso JC (2008) Morphometry of the human substantia nigra in ageing and Parkinson's disease. Acta Neuropathol 115, 461-470.

[18] Peters R (2006) Ageing and the brain. Postgrad Med J 82, 84-88.

[19] Ciaranello RD, Barchas R, Kessler S, Barchas JD (1972) Catecholamines: Strain differences in biosynthetic enzyme activity in mice. Life Sci I 11, 565-572.

[20] Tiplady B, Killian JJ, Mandel P (1976) Tyrosine hydroxylase in various brain regions of three strains of mice differing in spontaneous activity, learning ability, and emotionality. Life Sci 18, 1065-1070.

[21] Arenas E, Denham M, Villaescusa JC (2015) How to make a midbrain dopaminergic neuron. Development 142, 19181936.

[22] Blaess S, Ang SL (2015) Genetic control of midbrain dopaminergic neuron development. Wiley Interdiscip Rev Dev Biol 4, 113-134.

[23] Kim JH, Auerbach JM, Rodriguez-Gomez JA, Velasco I, Gavin D, Lumelsky N, Lee SH, Nguyen J, Sanchez-Pernaute R, Bankiewicz K, McKay R (2002) Dopamine neurons derived from embryonic stem cells function in an animal model of Parkinson's disease. Nature 418, 50-56.

[24] Zheng K, Heydari B, Simon DK (2003) A common NURR1 polymorphism associated with Parkinson disease and diffuse Lewy body disease. Arch Neurol 60, 722-725.

[25] Haubenberger D, Reinthaler E, Mueller JC, Pirker W, Katzenschlager R, Froehlich R, Bruecke T, Daniel G, Auff E, Zimprich A (2011) Association of transcription factor polymorphisms PITX3 and EN1 with Parkinson's disease. Neurobiol Aging 32, 302-307.

[26] Seidman JG, Seidman C (2002) Transcription factor haploinsufficiency: When half a loaf is not enough. J Clin Invest 109, 451-455.

[27] Lin W, Metzakopian E, Mavromatakis YE, Gao N, Balaskas N, Sasaki H, Briscoe J, Whitsett JA, Goulding M, Kaestner KH, Ang SL (2009) Foxa1 and Foxa2 function both upstream of and cooperatively with Lmx $1 \mathrm{a}$ and $\mathrm{Lmx} 1 \mathrm{~b}$ in a feedforward loop promoting mesodiencephalic dopaminergic neuron development. Dev Biol 333, 386-396.

[28] Nakatani T, Kumai M, Mizuhara E, Minaki Y, Ono Y (2010) Lmx1a and Lmx1b cooperate with Foxa2 to coordinate the specification of dopaminergic neurons and control of floor plate cell differentiation in the developing mesencephalon. Dev Biol 339, 101-113.

[29] Omodei D, Acampora D, Mancuso P, Prakash N, Di Giovannantonio LG, Wurst W, Simeone A (2008) Anteriorposterior graded response to Otx 2 controls proliferation and differentiation of dopaminergic progenitors in the ventral mesencephalon. Development 135, 3459-3470.

[30] Tang M, Villaescusa JC, Luo SX, Guitarte C, Lei S, Miyamoto Y, Taketo MM, Arenas E, Huang EJ (2010) Interactions of Wnt/beta-catenin signaling and sonic hedgehog regulate the neurogenesis of ventral midbrain dopamine neurons. J Neurosci 30, 9280-9291.

[31] Daniel B, Nagy G, Nagy L (2014) The intriguing complexities of mammalian gene regulation: How to link enhancers to regulated genes. Are we there yet? FEBS Lett 588, 23792391.

[32] Pierce SE, Tyson T, Booms A, Prahl J, Coetzee GA (2018) Parkinson's disease genetic risk in a midbrain neuronal cell line. Neurobiol Dis 114, 53-64.

[33] Coetzee SG, Pierce S, Brundin P, Brundin L, Hazelett DJ, Coetzee GA (2016) Enrichment of risk SNPs in regulatory regions implicate diverse tissues in Parkinson's disease etiology. Sci Rep 6, 30509.

[34] Zhu L, Sun C, Ren J, Wang G, Ma R, Sun L, Yang D, Gao S, Ning K, Wang Z, Chen X, Chen S, Zhu H, Gao Z, $\mathrm{Xu} J$ (2019) Stress-induced precocious aging in PD-patient iPSC-derived NSCs may underlie the pathophysiology of Parkinson's disease. Cell Death Dis 10, 105.

[35] Liu GH, Qu J, Suzuki K, Nivet E, Li M, Montserrat N, Yi F, Xu X, Ruiz S, Zhang W, Wagner U, Kim A, Ren B, Li Y, Goebl A, Kim J, Soligalla RD, Dubova I, Thompson J, Yates J, 3rd, Esteban CR, Sancho-Martinez I, Izpisua Belmonte 
JC (2012) Progressive degeneration of human neural stem cells caused by pathogenic LRRK2. Nature 491, 603-607.

[36] Byers B, Cord B, Nguyen HN, Schule B, Fenno L, Lee PC, Deisseroth K, Langston JW, Pera RR, Palmer TD (2011) SNCA triplication Parkinson's patient's iPSC-derived DA neurons accumulate alpha-synuclein and are susceptible to oxidative stress. PLoS One 6, e26159.

[37] Sanchez-Danes A, Richaud-Patin Y, Carballo-Carbajal I, Jimenez-Delgado S, Caig C, Mora S, Di Guglielmo C, Ezquerra M, Patel B, Giralt A, Canals JM, Memo M, Alberch J, Lopez-Barneo J, Vila M, Cuervo AM, Tolosa E, Consiglio A, Raya A (2012) Disease-specific phenotypes in dopamine neurons from human iPS-based models of genetic and sporadic Parkinson's disease. EMBO Mol Med 4, 380-395.

[38] Reinhardt P, Schmid B, Burbulla LF, Schondorf DC, Wagner L, Glatza M, Hoing S, Hargus G, Heck SA, Dhingra A, Wu G, Muller S, Brockmann K, Kluba T, Maisel M, Kruger R, Berg D, Tsytsyura Y, Thiel CS, Psathaki OE, Klingauf J, Kuhlmann T, Klewin M, Muller H, Gasser T, Scholer HR, Sterneckert J (2013) Genetic correction of a LRRK2 mutation in human iPSCs links parkinsonian neurodegeneration to ERK-dependent changes in gene expression. Cell Stem Cell 12, 354-367.

[39] Cooper O, Seo H, Andrabi S, Guardia-Laguarta C, Graziotto J, Sundberg M, McLean JR, Carrillo-Reid L, Xie Z, Osborn T, Hargus G, Deleidi M, Lawson T, Bogetofte H, PerezTorres E, Clark L, Moskowitz C, Mazzulli J, Chen L, Volpicelli-Daley L, Romero N, Jiang H, Uitti RJ, Huang Z, Opala G, Scarffe LA, Dawson VL, Klein C, Feng J, Ross OA, Trojanowski JQ, Lee VM, Marder K, Surmeier DJ, Wszolek ZK, Przedborski S, Krainc D, Dawson TM, Isacson O (2012) Pharmacological rescue of mitochondrial deficits in iPSC-derived neural cells from patients with familial Parkinson's disease. Sci Transl Med 4, 141ra190.

[40] Fernandez-Santiago R, Carballo-Carbajal I, Castellano G, Torrent R, Richaud Y, Sanchez-Danes A, Vilarrasa-Blasi R, Sanchez-Pla A, Mosquera JL, Soriano J, Lopez-Barneo J, Canals JM, Alberch J, Raya A, Vila M, Consiglio A,
Martin-Subero JI, Ezquerra M, Tolosa E (2015) Aberrant epigenome in iPSC-derived dopaminergic neurons from Parkinson's disease patients. EMBO Mol Med 7, 1529-1546.

[41] Oo TF, Burke RE (1997) The time course of developmental cell death in phenotypically defined dopaminergic neurons of the substantia nigra. Brain Res Dev Brain Res 98, 191196.

[42] Garcia-Reitboeck P, Anichtchik O, Dalley JW, Ninkina N, Tofaris GK, Buchman VL, Spillantini MG (2013) Endogenous alpha-synuclein influences the number of dopaminergic neurons in mouse substantia nigra. Exp Neurol 248, 541-545.

[43] Quilty MC, King AE, Gai WP, Pountney DL, West AK, Vickers JC, Dickson TC (2006) Alpha-synuclein is upregulated in neurones in response to chronic oxidative stress and is associated with neuroprotection. Exp Neurol 199, 249-256.

[44] Musgrove RE, King AE, Dickson TC (2011) Neuroprotective upregulation of endogenous alpha-synuclein precedes ubiquitination in cultured dopaminergic neurons. Neurotox Res 19, 592-602.

[45] Landreau F, Galeano P, Caltana LR, Masciotra L, Chertcoff A, Pontoriero A, Baumeister E, Amoroso M, Brusco HA, Tous MI, Savy VL, Lores Arnaiz Mdel R, de Erausquin GA (2012) Effects of two commonly found strains of influenza A virus on developing dopaminergic neurons, in relation to the pathophysiology of schizophrenia. PLoS One 7, e51068.

[46] Ling Z, Gayle DA, Ma SY, Lipton JW, Tong CW, Hong JS, Carvey PM (2002) In utero bacterial endotoxin exposure causes loss of tyrosine hydroxylase neurons in the postnatal rat midbrain. Mov Disord 17, 116-124.

[47] Iglesias E, Pesini A, Garrido-Perez N, Meade P, BayonaBafaluy MP, Montoya J, Ruiz-Pesini E (2018) Prenatal exposure to oxidative phosphorylation xenobiotics and lateonset Parkinson disease. Ageing Res Rev 45, 24-32.

[48] Carvey PM, Punati A, Newman MB (2006) Progressive dopamine neuron loss in Parkinson's disease: The multiple hit hypothesis. Cell Transplant 15, 239-250. 